Assiut Scientific Nursing Journal

http://asnj.journals.ekb.eg

http://www.arabimpactfactor.com

\title{
The Role of Work Locus of Control and Inclusive Leadership on Nurses' innovative Work Behavior
}

\author{
Wessam Ahmed Elsayed ${ }^{1}$, Asmaa Mustafa Abdel-Ghani ${ }^{2}$ \&Amira Abdel-Menem ${ }^{3}$ \\ 1. Assistant Professor of Nursing Administration, Nursing faculty, Mansoura University, Egypt. \\ 2. Lecturer of Nursing Administration, Nursing faculty, Mansoura University, Egypt. \\ 3. Lecturer of Nursing Administration, Nursing faculty, Mansoura University, Egypt.
}

\begin{abstract}
Background: Locus of control is an important variable that affects every area of human endeavor as describing individual differences and predicting behavior in organizational settings. Also, it is viewed as an important element for work motivation which determines the level of innovative behavior that helps health care providers to meet patients' needs. Motivating for nurses for innovative behavior largely rest on the leadership style. Aim: Investigate the role of work locus of control and inclusive leadership on nurses' innovative work behavior in Mansoura Gastroenterology surgical center. Methods: Descriptive analytical design was employed by 139 nursing staff working at Mansoura Gastroenterology surgical center, which affiliated at Mansoura University by using three tools as: work locus of control scale, inclusive leadership scale and innovative work behavior scale. Results: $89.9 \%$ of studied sample reported that the level of work locus of control was moderate, $(75.5 \%)$ of them mentioned that the inclusive leadership level was moderate and also, $(69.1 \%)$ of them mentioned that the level of innovative work behavior was moderate on their work setting. Conclusion: The work locus of control was not correlated significantly with innovative work behavior, but there was a highly positive correlation between inclusive leadership and innovative work behavior in studied settings. Recommendations: It is recommended that to promote innovative work behavior, it is necessary to managers cultivate an inclusive leadership style. Develop clear motivation system for nurses and provide them sufficient autonomy to think through and present new ideas. Hospital managers should develop training program continuously for enhancing nurses` locus of control.
\end{abstract}

\section{Keywords: Inclusive leadership, Innovative work behavior, Work locus of control.}

\section{Introduction}

The competitive health care environments motivate managers to find out strategies that encourage innovative behaviors among health care providers to meet patients' requirements that changed continuously (Chowhan, Pries, \& Mann, 2017; Hu, Wu, \& Gu, 2017). Until that time, many studies revealed that innovation was not focused only on research and development specialists but also concerned with other workers and specialties at all organizational levels that need to be opened in the direction of innovation within their particular roles for the long-term organizational achievements (Lee $\boldsymbol{\&}$ Wong, 2017\& Javed, et al, 2018)

The locus of Control refers to person's awareness of his or her capacity to have control over the environment. Work locus of control of employees refers to refers to how employees believe that they can control work events. (Shannak, \& Al-Taher, 2012)

Nurses with a high degree of internal control locus assume that their personal conduct and activities are primarily the product of their action. They also have well control of their performance and have tendency to reveal more administrative activities than externals and aim to inspire other people. They are more likely to believe that their actions would be successful and more involved than outsiders in finding information and awareness about their situation. Many with a high external control locus think that events are primarily controlled by powerful of others, fate, or chance. Although locus of control generally is repeatedly studied, restricted research has examined work locus of control (Fleur de Laat, 2016, \& Shannak \& Altaher, 2012)

The inclusive style is an extension relational leadership styles that emphasis on the interaction between leaders and subordinates, leaders stress on performing tasks with people rather doing things to people" (Carmeli et al., 2010 \& Hollander, 2012). The inclusive leadership defined as "words and actions by leaders that indicate an invitation and gratefulness for others' contributions." It also refers to as win-win situations with a common goals and ideas of mutually dependent relationships. The inclusive leaders are valued and person who accepted others within the organization and was accountable for results. Furthermore, an inclusive leader is playing a main role in establishing an inclusive organization (Li, 2019; Hollander, 2009 \& Ospina, 2011). 
The framework of inclusive leadership includes three dimensions: (I) leaders recognize, respect, design for human uniqueness and variability, logically tolerated to employee mistakes, also provide inspiration and support for the staff when they make errors. (II) Leaders use inclusive, open \& transparent processes, and co-operation with people who have a diversity of perspectives and praising accomplishments instead of showing distrust. (III) Leaders handle staff members equally, consider their needs and desires, display an adaptive behavior, and ensured that earnings were distributed fairly. Inclusive leadership has displayed a special nature of comprehensiveness, belonging, individuality, and inclusion in parallel with other types of leadership that may be abstractly connected (Qi, Liu, Wei \& Hu, 2019)

Inclusive leadership focuses on accepting the individual differences of employees, empowering them to contribute their specific abilities and viewpoints and encouraging them to participate in organizational goals. While servant leadership emphasis on employee improvements, inclusive leadership based on meeting the needs of employees for accessibility and transparency of the work community. While empowering leadership focused on leading by role model, distribution of power, training and teaching, it accelerates the awareness about accessibility and inclusiveness (Qi, Liu, Wei \& Hu, 2019)

The idea generation is the first stage of nurses' innovation. Overall honesty, availability and accessibility facilitated nurse disposition in creative work (Widmann \& Mulder, 2018; Ye et al., 2019; Kremer et al., 2019). Innovative work behavior (IWB) improves the performance quality that increases the usefulness of services delivered by nursing staff and improving the possibility and spirit of new idea generating. Inclusive leadership is an extraordinary feature that reshapes nurses' attention to support and promote creative work behavior (Alshoukri, et al, 2020)

Innovative Work Behavior (IWB) has a vital role in accomplishing the goal of the organization. It is deal with employees' accomplishments and desires to improve the existing environments (Akram et al., 2016; \& Alsughayir, 2017). IWB is particularly significant for entire organizational health care professionals not only important for the innovationoriented organizations or departments (Alshoukri, et al, 2020).

\section{Significance of the study}

Innovation is the central facilitator for organizational development, performance, and effectiveness. Managers and leaders have progressively highlighted the significant effect of innovation for competitive advantages, supportable development, and long-term organizational achievement. The key issue of innovation was that a nurse had an innovative, new and creative idea and developed that idea away from its first state. Assumed that nurse innovation in health care organizations was the vital importance to an organization, as it is the basic element to recognize factors that encourage nurse innovative behavior, which improves nurse's engaging innovative activities (Qi, Liu, Wei \& Hu, 2019). Even with broad literature about inclusive leadership and its impact on innovative behavior, few studies have discovered the relationship between inclusive leadership and innovative behavior of nurses. To deal with this gap, this study aims to investigate how work locus of control and inclusive leadership influence on nurses' innovative work behavior

Aim of the study

The aim of this study is to investigate the influence of work locus of control and inclusive leadership on nurses' innovative work behavior in Mansoura Gastroenterology surgical center

Research Questions:

- What is the level of work locus of control in Mansoura Gastroenterology surgical center?

- What is the level of inclusive leadership in Mansoura Gastroenterology surgical center?

- What is the level of innovative work behavior in Mansoura Gastroenterology surgical center?

- What is the influence of work locus of control and inclusive leadership on nurses' innovative work behavior in Mansoura Gastroenterology surgical center?

\section{Subjects and Methods \\ Research design}

Descriptive correlational research design was utilized. Research Setting:

The study was conducted at Mansoura Gastroenterology surgical center. It is the fourth center specializing in gastrointestinal surgery in the world.it provides medical care for specific patient with different liver diseases. It also includes training programs for Egyptian and foreign physicians around the world. It includes operating rooms, intensive care unit, internal department, medical unit, endoscopy unit and radiology unit

Participants: All available nurses (139 nurses) at Mansoura Gastroenterology surgical center at previously mentioned units and accepted to participate in the study were selected through convenient sampling.

Tools of data collection: Three questionnaires were utilized for data collection. $\mathbf{1}^{\text {st }}$ questionnaire consists of two parts. $1^{\text {st }}$ part is demographic data of studied sample as age, years of experience, education level.... 
etc. The $2^{\text {nd }}$ part includes work locus of control scale that adopted from (Spector, 1988) and contains (16) items. It aims to assess the work locus of control through five (5) point Likert scale ranged from strongly disagree (1) to strongly agree (5).

Scoring system: Based on cut of value $50 \%$, the level of work locus of control is set as low $<50 \%$, moderate $50-75 \%$ and high $>75 \%$

The $\mathbf{2}^{\text {nd }}$ questionnaire is inclusive leadership scale adopted from (van Dierendonck \& Nuijten, 2011) that contains (17) items and aims to assess the inclusive leadership through Five (5) point Likert scale ranged from (1) strongly disagree to (5) strongly agree.

Scoring system: Based on cut of value $50 \%$, the level of inclusive leadership is set as low $<50 \%$, moderate $50-75 \%$ and high $>75 \%$

$\mathbf{3}^{\text {rd }}$ questionnaire is IWB scale adopted from Janssen, (2000) and contains three (3) items namely Idea Generation, Idea Promotion contains and Idea Realization each item contains three (3) sub items with total nine (9) sub items.

Scoring system: Based on cut of value $50 \%$, the level IWB is set as low $<50 \%$, moderate $50-75 \%$ and high $>75 \%$

\section{Validity and reliability:}

Five experts of nursing administration were tested tools for its face and content validity. The study tools were tested to assess reliability via the pilot subjects and Cronbach's alpha test was 0.879 for first tool, 0.899 for the second tool and 0.879 for third tool.

\section{Pilot study:}

A pilot study was administrated on $10 \%$ from nurses (14 nurses) at Mansoura Gastroenterology surgical center that excluded from the study contributors to assess the clearness, applicability of tools and determine the time needed to fill in questions. No modifications were needed.
Field work:

The researchers introduced themselves to the study sample, explained the aim of the study, and the way to fill the questionnaire, approval was taken orally and asked them for their cooperation with them. The researchers met the respondents either individually or groups during shifts to distribute the questionnaires during these meetings. The respondents filled in the tools individually at once and some respondents read the questionnaires and fixed another time to fill them, filling the questionnaire sheet acquired from 20-30 minutes. The data collection process started from the beginning of September to the end of November, 2019

\section{Ethical considerations}

The Research Ethical Committee of Faculty of Nursing, Mansoura University was awarded an approval for the current study. An official permission to conduct the study was obtained from the responsible administrator of the Gastroenterology surgical center. The participation in the study was voluntary and participants have the right to withdraw from the study at any time. All participants were assured about the confidentiality of the collected data and therefore the privacy of the study sample was assured.

\section{Statistical techniques:}

The data were analyzed statistically by using SPSS software version 22. Categorical variables were represented as frequency and percentage. Continuous variables were represented as mean, and standard deviation. Independent t-test was used to test the difference between two mean of continuous variables. ANOVA test used to test the difference between more than two mean of continuous variables. Pearson correlation coefficient test was conducted to test the association between two continuous variables. Statistically significant was at p-value $\leq 0.01 \& 0.05$.

\section{Results}

Table (1): Personal characteristics of the nursing staff ( $n=139)$.

\begin{tabular}{|c|c|c|}
\hline \multicolumn{1}{|c|}{ Variables } & No & $\%$ \\
\hline Age years: & & 21.6 \\
\hline - $20-<25$ & 30 & 37.4 \\
\hline - $25-<30-<35$ & 52 & 25.9 \\
\hline - $35-<40$ & 36 & 8.6 \\
\hline Gender $>40$ & 12 & 6.5 \\
\hline - Male & 9 & 15.1 \\
\hline Level of education & 21 & 84.9 \\
\hline - Diploma nurse & 118 & 27.3 \\
\hline - Technical institute & & 46.0 \\
\hline
\end{tabular}




\begin{tabular}{|c|c|c|}
\hline Work position & & \\
\hline$\cdot$ Nurse & 133 & 95.6 \\
\hline$\cdot$ Head nurse & 3 & 2.2 \\
\hline$\cdot$ Supervisor & 3 & 2.2 \\
\hline Workplace & & 46.0 \\
\hline$\cdot$ Intensive care unit & 64 & 18.0 \\
\hline$\cdot$ Internal department & 25 & 10.1 \\
\hline$\cdot$ Medical unit & 14 & 15.8 \\
\hline$\cdot$ Endoscopy unit & 22 & 8.6 \\
\hline$\cdot$ Radiology unit & 12 & 1.4 \\
\hline Operating room & 2 & 32.4 \\
\hline Experience years: & & 26.6 \\
\hline$\cdot \quad 1-<5$ & 45 & 15.8 \\
\hline$\cdot$ 5-<10 & 37 & 18.7 \\
\hline$\cdot$ - $10-<15$ & 22 & 6.5 \\
\hline$\cdot>20$ & 26 & \\
\hline
\end{tabular}

Table (2): Mean scores of work locus of control, inclusive leadership, and IWB as perceived by the nursing staff $(\mathbf{n}=139)$.

\begin{tabular}{|c|c|c|c|}
\hline Variables & No of items & Min- max & Mean \pm SD \\
\hline 1. Work locus of control & 16 & $33.0-65.0-$ & $51.78 \pm 5.75$ \\
\hline $\begin{array}{ll}2 . & \text { Inclusive leadership }\end{array}$ & 17 & $38.0-85.0$ & $57.64 \pm 7.93$ \\
\hline 3. $\quad$ IWB & 9 & $26.0-40.0$ & $32.20 \pm 3.17$ \\
\hline - Idea Generation & 3 & $7.0-14.0-$ & $10.53 \pm 1.59$ \\
\hline - Idea Promotion & 3 & $7.0-14.0$ & $10.81 \pm 1.46$ \\
\hline - Idea Realization & 3 & $8.0-14.0$ & $10.84 \pm 1.32$ \\
\hline
\end{tabular}

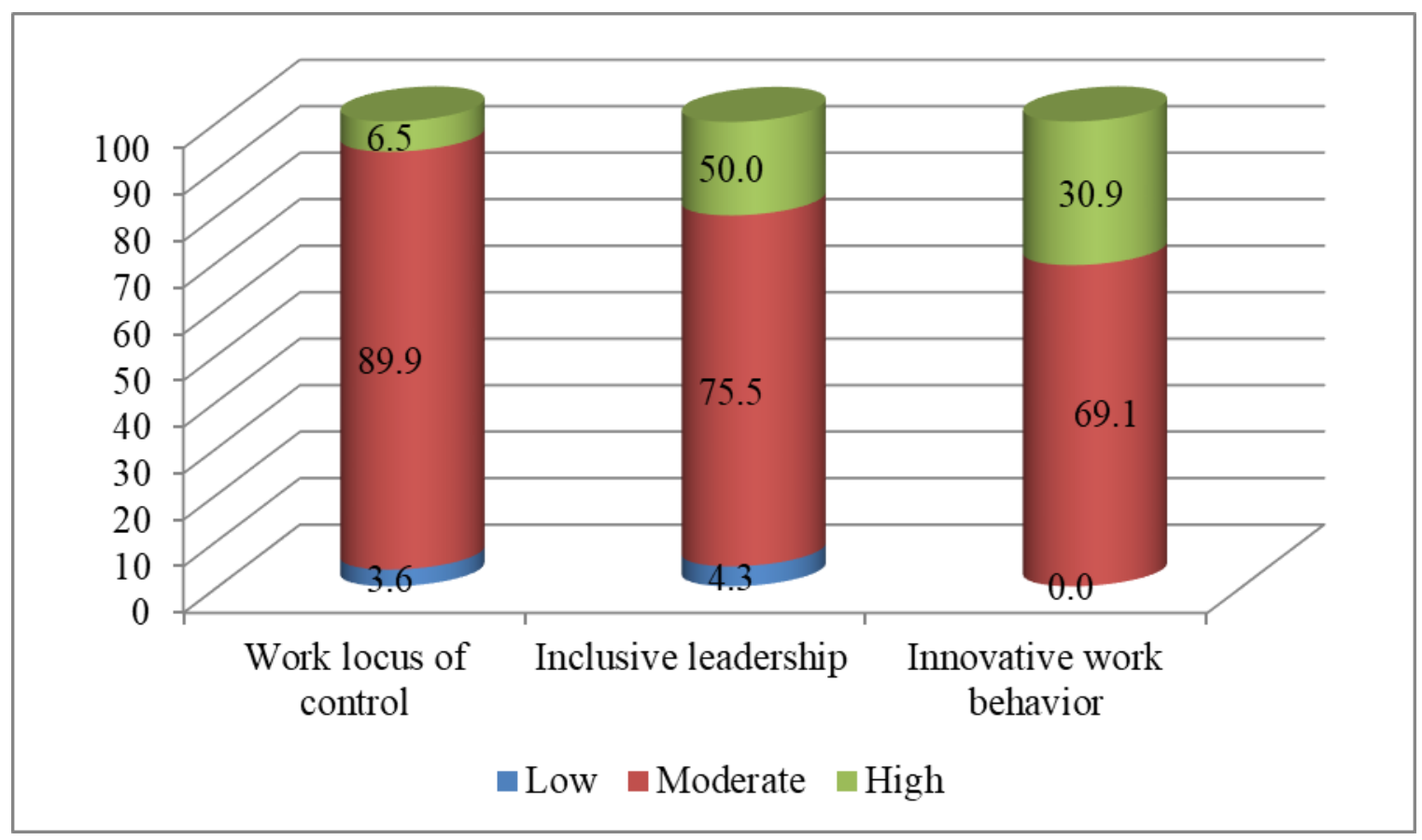

Figure (1): Levels of work locus of control, inclusive leadership, and IWB among the nursing staff $(n=139)$. 
Table (3): Mean scores of work locus of control, inclusive leadership, and IWB in relation to personal characteristics of the nursing staff $(n=139)$

\begin{tabular}{|c|c|c|c|}
\hline Variables & $\begin{array}{c}\text { Work locus of } \\
\text { control }\end{array}$ & $\begin{array}{c}\text { Inclusive } \\
\text { leadership }\end{array}$ & IWB \\
\hline Age & Mean \pm SD & Mean \pm SD & Mean \pm SD \\
\hline - $20-<25$ & $52.90 \pm 5.47$ & $58.76 \pm 9.44$ & $32.36 \pm 2.82$ \\
\hline - $25-<30$ & $52.28 \pm 5.77$ & $56.98 \pm 7.83$ & $31.98 \pm 3.42$ \\
\hline - $\quad 30-<35$ & $51.25 \pm 5.37$ & $58.22 \pm 7.16$ & $32.38 \pm 3.53$ \\
\hline - $35-<40$ & $50.58 \pm 6.41$ & $57.56 \pm 6.79$ & $32.66 \pm 1.43$ \\
\hline - $>40$ & $48.88 \pm 6.84$ & $56.00 \pm 8.38$ & $31.55 \pm 3.46$ \\
\hline F-value /p value & $1.16 / 0.32$ & $0.38 / 0.81$ & $0.26 / 0.90$ \\
\hline \multicolumn{4}{|l|}{ Gender } \\
\hline - Male & $49.76 \pm 8.06$ & $56.66 \pm 7.53$ & $31.28 \pm 2.53$ \\
\hline - Female & $52.14 \pm 5.19$ & $57.81 \pm 8.02$ & $32.36 \pm 3.26$ \\
\hline t-value /p value & $1.76 / 0.08$ & $0.61 / 0.54$ & $1.43 / 0.15$ \\
\hline \multicolumn{4}{|l|}{ Level of education } \\
\hline - Diploma nurse & $52.68 \pm 6.52$ & $57.57 \pm 7.36$ & $32.39 \pm 3.09$ \\
\hline - $\quad$ Technical institute & $52.28 \pm 4.48$ & $58.93 \pm 7.92$ & $32.09 \pm 3.36$ \\
\hline - $\quad$ Bachelor of nursing & $50.00 \pm 6.57$ & $55.45 \pm 8.24$ & $32.18 \pm 2.98$ \\
\hline f-value /p value & $2.54 / 0.08$ & $2.29 / 0.11$ & $0.11 / 0.90$ \\
\hline \multicolumn{4}{|l|}{ Work position } \\
\hline - Nurse & $51.71 \pm 5.83$ & $57.60 \pm 8.08$ & $32.23 \pm 3.21$ \\
\hline - $\quad$ Head nurse & $52.33 \pm 4.04$ & $57.00 \pm 5.00$ & $32.66 \pm 1.52$ \\
\hline - $\quad$ Supervisor & $54.33 \pm 2.31$ & $59.66 \pm 1.15$ & $30.33 \pm 2.88$ \\
\hline f-value /p value & $0.31 / 0.73$ & $0.10 / 0.89$ & $0.55 / 0.57$ \\
\hline \multicolumn{4}{|l|}{ Workplace } \\
\hline - Intensive care unit & $52.00 \pm 4.34$ & $56.95 \pm 8.71$ & $32.62 \pm 3.23$ \\
\hline - $\quad$ Internal department & $50.80 \pm 8.17$ & $58.08 \pm 8.11$ & $32.80 \pm 2.94$ \\
\hline - $\quad$ Medical unit & $51.42 \pm 6.51$ & $58.28 \pm 4.64$ & $30.14 \pm 2.24$ \\
\hline - $\quad$ Endoscopy unit & $51.36 \pm 6.58$ & $56.90 \pm 7.92$ & $32.09 \pm 3.70$ \\
\hline - $\quad$ Radiology unit & $54.66 \pm 3.47$ & $61.91 \pm 5.16$ & $31.75 \pm 2.17$ \\
\hline - $\quad$ Operating room & $47.00 \pm 0.00$ & $52.00 \pm 9.89$ & $29.50 \pm 4.94$ \\
\hline f-value /p value & $1.08 / 0.37$ & $1.06 / 0.38$ & $1.99 / 0.08$ \\
\hline \multicolumn{4}{|l|}{ Experience years: } \\
\hline . $1-<5$ & $50.95 \pm 6.95$ & $57.37 \pm 9.20$ & $31.71 \pm 2.78$ \\
\hline - $5-<10$ & $54.02 \pm 3.96$ & $58.45 \pm 7.26$ & $32.62 \pm 3.42$ \\
\hline - $10-<15$ & $50.63 \pm 6.90$ & $56.54 \pm 7.64$ & $31.68 \pm 3.28$ \\
\hline - $15-<20$ & $50.92 \pm 4.62$ & $58.11 \pm 6.73$ & $33.19 \pm 3.17$ \\
\hline - $\quad>20$ & $52.00 \pm 2.95$ & $56.88 \pm 8.92$ & $31.33 \pm 3.46$ \\
\hline f-value /p value & $2.07 / 0.88$ & $0.25 / 0.91$ & $1.39 / 0.24$ \\
\hline
\end{tabular}




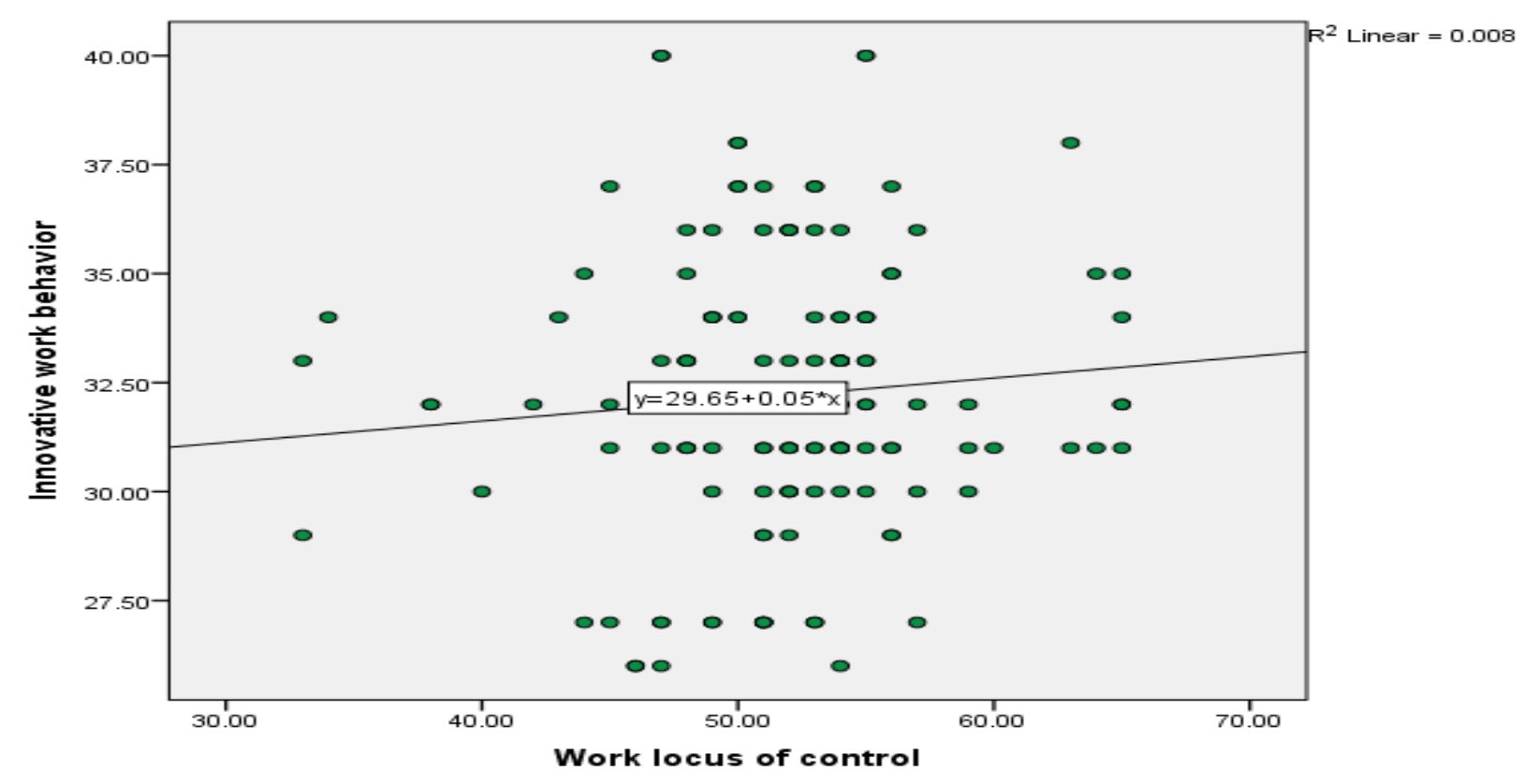

Figure (2): Relationship between work locus of control and IWB of the nursing staff ( $n=139)$

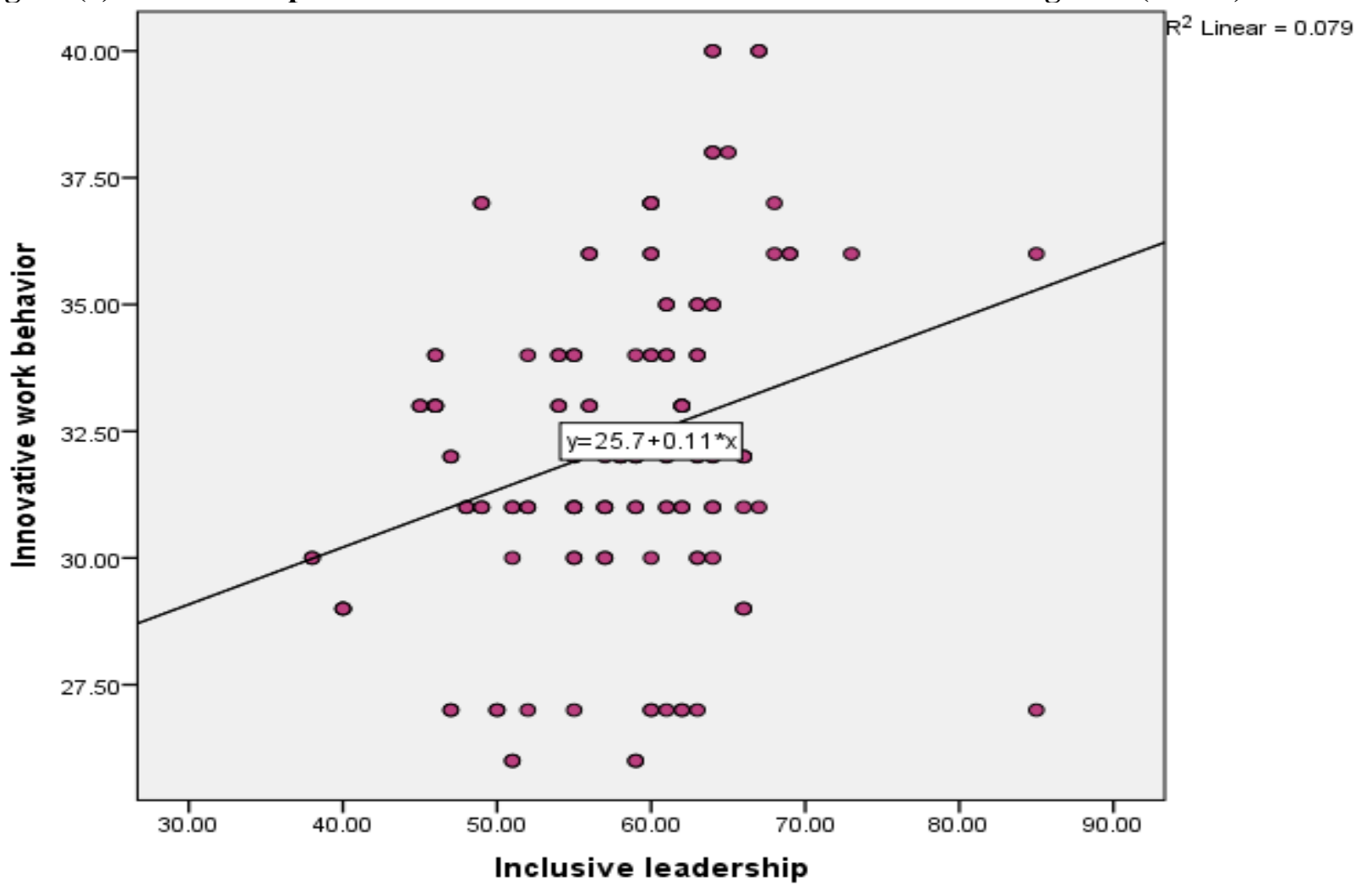

Figure (3): Relationship between inclusive leadership, and IWB of the nursing staff $(n=139)$ 
Table (1): Shows that (37.4\%) from studied sample aged from 26-30 years old, $(84.9 \%)$ of them were female, $(46 \%)$ of them had a technical institute, $(95.7 \%)$ of them were nurses, $(46 \%)$ working in intensive care unit and $(32.4 \%)$ of them had from 1-5 years of experience.

Table (2): Shows that the studied sample reported their high mean scores for inclusive leadership (38.085.0) followed by work locus of control (33.0-65.0-) while IWB gained the lowest mean scores (26.040.0).

Figure (1): illustrates that $(89.9 \%)$ of studied sample reported that the level of work locus of control was moderate, $(75.5 \%)$ of them mentioned that the inclusive leadership level was moderate and also, $(69.1 \%)$ of them mentioned that the level of IWB was moderate on their work setting.

Table (3): Illustrates that there was no statistically significant differences of nurses' work locus of control, inclusive leadership, and IWB related to their personal characteristics.

Figure (3): Illustrates that there is a highly positive correlation between inclusive leadership and IWB in studied settings.

\section{Discussion}

Innovation is a critical factor for supporting continuous changes in health care environments. It arises when a nurse develops, improves and applies new ideas that are main components of nurses' IWB. Research revealed that leadership, team work, work climate, personal characteristics, job resources and job demand, personal attitudes and values, are obviously related to the IWB. Among all these indicators of IWB, leadership shows a significant role on nurses' IWB (Franco \& Haase, 2016). Inclusive leaders provide their subordinates with participation in decision-making and work activities, demonstrate their availability to subordinates; therefore, they support their staff to have new and innovative ideas. Generating fresh ideas is the first phase of IWB (Sharifirad \& Ataei, 2012).

Regarding total locus of control level of the nursing staff, the results of current study revealed that there is moderate level of work locus of control, this may be due to most of the studied nurses make their duties for accomplishing a specific task or goal and liable for success, this provides a degree of control. This result was agreed with El-Sayed \& Abdel-Aleem, (2014) who found that, about three fifth of head nurses have internal locus of control, while more than two fifth of them have external other locus of control. Similarity, locus of control shows a significant role individual's lives, particularly in the labor setting. Furthermore, the locus of control characteristics had a significant relationship with the presence in the workplace.
Locus of control is linked with desirable work outcomes although the shortage of internal locus of control is associated with undesirable work outcomes and behaviors Sahraian \& Ghanizadeh (2014).

Also, this result was in the same line of Kalil, et al, (2019) who revealed in their study about; relationship among nurses 'locus of control, work motivation factors, and their organizational commitment that more than half of studied staff nurses' had locus of control. On the opposite hand, this result was in disagreement with Pourhoseinzadeh, et al. (2017), who revealed in their study about; the relationship between health locus of control and health behaviors in emergency medicine to determine the type of health locus of control in emergency medical personnel show that maximum of workers had external locus of control.

Regarding total inclusive leadership level, the results of current study revealed that the level of inclusive leadership was moderate. This may be related to leader encourages nurses to use their abilities, helps nurses to further improve themselves and encourages nurses to solve problems instead of just telling them the way to solve it.

These findings were supported by Franco\& Haase (2016) who stated that inclusive leaders respect and inspire nurses to achieve hard and challenging goals, identify and evaluate their efforts and achievements to realize those definite goals, and show reactive behavior where leaders respond clearly and timely to personnel' problems. Furthermore, they delegated power to staff, with high autonomy to do their work activities on their way. They appreciated the presence of staff at work setting Salib (2014)

The present study highlighted that level of IWB was moderate. This may be related to nurses mobilizing support for innovative ideas, generating original solutions for problems after evaluating its utility. These findings accept as true with Kratzer, et al (2012) showed that IWB is complex, non-routine behavior where staff generate innovative ideas, avoided traditional thoughts and refuse superiors through challenging the status quo, in such an environment it was understood that a lot of the new ideas were intended to fail.

On the opposite side, employees who express new progress were rejected because it was supposed as unfamiliar behavior at work environment. Consequently, leaders considered creative employees as trouble makers. These employees faced the experience of punishment like downgrading or termination regarding their innovativeness (Gong et al., 2012).

The current study indicated that there was a highly positive relationship between inclusive leadership and IWB in studied settings. This might be due to 
inclusive leadership is a practice of interactive leadership, openly involving employees in decisionmaking, and permitted them to express participative behavior in the work environment. Consequently, in an inclusive environment where personnel experienced high support from their leaders, IWB stimulated. These findings accept as true with (Javed, et al, 2018) who study inclusive leadership and IWB: The role of psychological empowerment and mentioned that positive relation between inclusive leadership and IWB.

This finding was congruent with the study of (Choi, et al, 2017) who studies inclusive leadership and employee well-being: The mediating role of personjob fit and reported that positive relation between inclusive leadership and innovative behavior in employees in Vietnam. This is the same line of Javed et al, (2017) examined the relationship between inclusive leadership and IWB among supervisorsubordinate in Pakistan. Their findings confirmed that inclusive leadership completely affected IWB. Employees were involved in the innovative practices and they had excellent relationship with their leaders that inspired them to take risks for idea generation, implementation and promotion.

Moreover, inclusive leadership shows honesty to listen to new ideas, show their presence of leaders as employees confront challenges and have the ability to discuss urgent events with employees. Accordingly, workers can simply share and discuss the main problems they face while exhibiting IWB (Masood, M., \& Afsar. 2017). As well as, Inclusive culture the leader accepts the employees' faults and disappointment to achieve desired goals. Regarding accepting disappointment, inclusive leadership managers have the responsibility for disappointment as a result, encouraging employees to point out more IWB (Afsar, et al, 2014)

The findings of the study revealed that, there was no significant correlation between work locus of control and IWB in studied setting. Within the same line of (Škudienė, et al., 2018) who found that neither internal locus of control nor external locus of control has shown statistically significant relationship with IWB. On the contrary, lately other dimensions have started to come into play in IWB. Locus of control is one among these dimensions, which is considered as a personality variable. The superiority of internal locus of control, especially with respect to creativity and innovation Kaur \& Gupta, (2016)

This finding disagreed with Kaur \& Gupta (2016) found that locus of control, has a positive relation and is a strong predictor of innovative behavior. Also, in contrary with the current study findings a study conducted by, (Pasaribu, et al, 2019) concluded that, locus of control has a positive direct influence on the innovative behavior, innovative behaviors are very much determined by the level of locus of control of each teacher in the school. Similarity, Lingyan, et al., (2020) in their study of effect of locus of control on innovative behavior among new generation employees: A moderate mediation role identified that internal locus of control had direct and indirect positive effects on innovative behavior and external locus of control had direct and indirect negative effects on innovative behavior.

\section{Conclusion}

Current research indicated that no correlation between LOC and IWB while, there was positive correlation between inclusive leadership and IWB. So, we can have concluded that inclusive environment where employees perceived high support from their leaders, IWB stimulated

\section{Recommendation}

Based on the findings of this study, the following can be recommended: -

1- Provide a motivation program with respect to innovative activities, such as extra payment, extraordinary gifts for greatest ideas, or any other means of tangential rewards, as long as they are appreciated from the employees

2- Give nurses sufficient autonomy to think about new ideas that provides worthy opportunity to develop more creative and innovative concepts, without strict boundaries and stress from the management levels.

3- Encourage continuous in-service training program for enhancing nurses` locus of control.

4- Take into considerations individual dissimilarities of nurses when applying different leadership styles in work setting, as their effectiveness can be influenced by the personality characteristics of nurses with respect to locus of control

5- Make brainstorming sessions to improve innovative work behavior

6- Encourage an inclusive culture by highlighting honesty, accessibility and availability to provide chance for nurses to create new ideas and express their opinions. Therefore, it is almost important for nursing leaders to provide training programs to foster a close relationship with nurses

\section{Reference}

- Afsar, B., Badir, Y., Saeed, B., \& Hafeez, S. (2017): Transformational and transactional leadership and employee's entrepreneurial behavior in knowledge-intensive industries. The International Journal of Human Resource Management, 28(2), 307-332. 
- Akram, T., Leia, S., \& Haidera, M. (2016): The impact of relational leadership on employee innovative work behavior in IT industry of China. Arab Economic and Business Journal, 08 June, p. 09.

- Alshoukri, Kh., Karim, A., \& Farhana, N. (2020): The Impact of Leadership on Employee Innovative Work Behaviour in Facilities Management Service Providers in Oman, International Journal of Academic Research in Accounting, Finance and Management Sciences, s $10 \quad(1)$ : 71-84, http://dx.doi.org/10.6007/IJARAFMS/v10-i1/6993 (DOI: 10.6007/IJARAFMS/v10-i1/6993)

- Alsughayir, A. (2017): The Effect of LeaderMember Exchange on Innovative Work Behavior in the Saudi Hospitality. International Journal of Business and Management, 12(6), 189 - 195.

- Carmeli, A., Reiter-Palmon, R., \& Ziv, E. (2010): Inclusive leadership and employee involvement in creative tasks in the workplace: The mediating role of psychological safety. Creativity Research Journal, 22(3), 250-260

- Choi, S., Tran, T., \& Kang, S. (2017): Inclusive leadership and employee well-being: The mediating role of person- job fit. Journal of Happiness Studies, 18(6), 1877-1901

- Chowhan, J., Pries, F., \& Mann, S. (2017): Persistent innovation and the role of human resource management practices, work organization, and strategy. Journal of Management \& Organization,23(3), 456-471

- El-Sayed, R., \& Abdel-Aleem, M. (2014). Relationship between head nurses' locus of control and staff nurses' job empowerment Med. J. Cairo Univ., 82(1).

- Fleur de Laat, A., (2016): The effect of work locus of control on the relationship between inclusive leadership and work engagement, published master thesis, Tilburg University, available at http://arno.uvt.nl/show.cgi?fid=142129

- Franco, M., \& Haase, H. (2016). Collective entrepreneurship: Employees' perceptions of the influence of leadership styles. Journal of Management \& Organization,1-17.

- Gong, Y., Cheung, S., Wang, M., \& Huang, J. C. (2012): Unfolding the proactive process for creativity: Integration of the employee proactivity, information exchange, and psychological safety perspectives. Journal of Management, 38(5), 1611-1633.

- Hollander, E. (2012): Inclusive leadership: The essential leader-follower relationship. Routledge.

- Hu, N., Wu, J., \& Gu, J. (2017): Cultural intelligence and employees' creative performance: The moderating role of team conflict in inter organizational teams. Journal of Management \& Organization, 1-21. https://doi.org/10.1017/jmo.2016.64.

- Janssen, O., (2000): "Job demands, perceptions of effort-reward fairness and innovative work behaviour," Journal of Occupational and Organizational Psychology, vol. 73, 2000, pp. 287-30

- Javed, B., Abdullah, I., Zaffar, M., Haque, A., \& Rubab, U., (2018): Inclusive leadership and innovative work behavior: The role of psychological empowerment, Journal of Management \& Organization 25(04):1-18, available

at

https://www.researchgate.net/publication/3276550

14 Inclusive leadership and innovative work be havior The role_of psychological_empowerment

- Javed, B., Naqvi, S., Arjoon, S., \& Tayyeb, H. (2017): Impact of inclusive leadership on innovative work behavior: The role of psychological safety. Journal of Management \& Organization, 23,1-20.

- Kalil, S., Abd-Elrhaman1, E., \& Sliman,W. (2019): Relationship among Nurses 'Locus of Control, Work Motivation Factors, and Their Organizational Commitment. American Journal of Nursing Research,, Vol. 7, No. 2, 167-178, DOI:10.12691/ajnr-7-2-8

- Kratzer , J., Kessel, M \& Weber, H. (2012): Innovative Work Behavior in Healthcare: The Benefit of Operational Guidelines in the Treatment of Rare Diseases, Health Policy 105(2-3):146-53, DOI: 10.1016/j.healthpol.2012.02.010

- Kaur, K., \& Gupta, V. (2016): The Impact of Personal Characteristics on Innovative Work Behaviour: An Exploration into Innovation and Its Determinants amongst Teachers. The International Journal of Indian Psychology, 3 (3/11), 158-172.

- Kremer, H., Villamor, I., \& Aguinis, H. (2019): Innovation leadership: Best-practice recommendations for promoting employee creativity, voice, and knowledge sharing. Business Horizons, 62(1), 65-74.

- Lee, C., \& Wong, C. (2017): The effect of team emotional intelligence on team process and effectiveness. Journal of Management \& Organization, 1-16.

- Li, Y., (2019): Impact of Inclusive Leadership on Employees' Adaptive Performance, Advances in Economics, Business and Management Research, volume

(http://creativecommons.org/licenses/by-nc/4.0/

- Lingyan , Xu, Jianguo, Du., Xiying Lei, \& Keith, W. (2020): Effect of locus of control on innovative behavior among new generation employees: A moderated mediation model, Social 
Behavior and personality an international journal, $48 \quad$ (10) , $\quad$ https://www.sbpjournal.com/index.php/sbp/article/view/9379

- Masood, M., \& Afsar, B. (2017): Transformational leadership and innovative work behavior among nursing staff. Nursing Inquiry, 24(4), 1-4.

- Miceli, M., Near, J., \& Dworkin, T. (2009): A word to the wise: How managers and policymakers can encourage employees to report wrongdoing. Journal of Business Ethics, 86(3), 379-396.

- Ospina, S. (2011): Leadership, Diversity and inclusion: Insights from scholarship. Graduate School of Public Service, 3(1): 3-30

- Pasaribu, L., Purba, S., \& Pangaribuan, W. (2019): The Effect of Locus of Control, Work Environment, and Innovative Behavior on Teachers Work Commitment, 4th Annual International Seminar on Transformative Education and Educational Leadership, Advances in Social Science, Education and Humanities Research, volume 384

- Pourhoseinzadeh, M., Gheibizadeh, M., Moradikalboland, M., \& Cheraghian, B. (2017): The relationship between health locus of control and health behaviors in emergency medicine. IJCBNM. 5(4): 397-407

- Qi, L., Liu, B., Wei, X., \& Hu, Y. (2019): Impact of inclusive leadership on employee innovative behavior: Perceived organizational support as a mediator, available https://doi.org/10.1371/journal.pone.0212091

- Sahraian,A., \& Ghanizadeh,A., (2014): Association of Job Stress with Locus of Control in Nurses. Shiraz E Medical Journal ,15(2), DOI: $10.17795 /$ semj20588

- Salib, E., (2014): A model of inclusion and inclusive leadership in the US (Doctoral dissertation). Rutgers University, Graduate School, New Brunswick.

- Shannak, R., \& Al-taher, A. (2012): Factors affecting Work Locus of Control: An Analytical and Comparative Study, Jordan Journal of Business Administration 8(2):373-389, available at https://www.researchgate.net/publication/2579473 05_Factors affecting_Work_Locus_of_Control_A n_Analytical_and_Comparative_Study

- Sharifirad, M., \& Ataei, V. (2012): Organizational culture and innovation culture: Exploring the relationships between constructs. Leadership \& Organization Development Journal, 33(5), 494-517

- Škudienė, V., Kvedaravičienė, I., Demeško, N., \& Suchockis, N.,(2018):Exploring the relationship between innovative work behavior and leadership: moderating effect of locus of control. ORGANIZATIONS AND MARKETS IN EMERGING ECONOMIES, 2018, VOL. 9, No. $1(17)$ https://doi.org/10.15388/omee.2018.10.00002

- Spector, P. (1988): Development of work locus of control scale. Journal of Occupational Psychology, 61(4), 335-340.

- Van Dierendonck, D., \& Nuijten, I. (2011). The servant leadership survey: Development and validation of a multidimensional measure. Journal of business and psychology, 26(3), 249-267

- Widmann, A., \& Mulder, R. (2018): Team learning behaviors and innovative work behaviour in work teams. European Journal of Innovation Management, 21(3), 501-520.

- Xu, L., Du, J., Lei, x., \& Keith, W. (2020): Effect of locus of control on innovative behavior among new generation employees: A moderated mediation model. Social Behavior and Personality: an international journal, Volume 48, Number 10, 2020, pp. 1-12(12) DOI: https://doi.org/10.2224/sbp.9379.

- Ye, Q., Wang, D., \& Guo, W. (2019): Inclusive leadership and team innovation: The role of team voice and performance pressure. European Management Journal. 